\title{
Scientific literacy materi fluida statis siswa SMA: studi kasus
}

\author{
Lestari Widodo, Lia Yuliati, dan Parno \\ Pascasarjana Pendidikan Fisika, Universitas Negeri Malang \\ Jl. Semarang 5 Malang \\ Surat-e: widodosmile@yahoo.co.id
}

\begin{abstract}
Penelitian ini bertujuan untuk mendeskripsikan scientific literacy siswa sebelum dan setelah pembelajaran STEM berbasis masalah pada materi fluida statis. Metode penelitian ini adalah metode dekriptif pada salah satu kelas di SMAN 8 Muaro Jambi. Subjek penelitian ini terdiri atas 27 siswa yang meliputi I9 perempuan dan 8 laki-laki. Scientific literacy siswa diukur menggunakan 5 butir soal essai. Soal tersebut telah valid dan memiliki reliabilitas yang tinggi. Hasil analisis n-gain menunjukkan bahwa terdapat peningkatan. N-gain rata-rata masingmasing soal menunjukkan n-gain soal nomor I sebesar 0,23 (rendah), soal nomor 2 sebesar 0,46 (sedang), soal nomor 3 sebesar 0,25 (rendah), soal nomor 4 sebesar 0,I56 (rendah), dan soal nomor 5 sebesar 0,625 (tinggi). Berdasarkan jawaban post-test siswa diperoleh kriteria scientific literacy siswa. Kriteria tersebut berdasarkan kriteria PISA 2015.
\end{abstract}

The purpose of this study was to describe the students' scientific literacy before and after STEM based on problem learning on static fluid. The method of this study was the descriptive method in one of class in SMAN 8 Muaro Jambi. The subjects were 27 students who consisted of 19 females and 8 males. The students' scientific literacy was measured by 5 essay questions. The instrument was valid and had the high reliability. The analyzed results of $\mathrm{n}$-gain show that there is an improvement. The average of n-gain for each question shows that the n-gain of the numbers show 0,23 (low) in number I, 0.46 (medium) in number 2, 0,25 (low) in number 3, 0,I56 (low) in number 4 and 0,625 (medium) in number 5. Based on the students' post-test it gains the students' scientific literacy criteria. It's based on PISA 2015.

Kata kunci: STEM, Scientific Literacy, Fluida Statis

\section{Pendahuluan}

Salah satu mata pelajaran pada tingkat Sekolah menengah atas ialah fisika. Melalui pengetahuan fisika, siswa dapat menjelaskan fenomena-fenomena dalam kehidupan sehari-hari. Dengan demikian, fenomena dapat dideskripsikan secara ilmiah.

Kemampuan menjelaskan fenomena dalam kehidupan sehari-hari secara ilmiah lebih dikenal dengan scientific lieracy. Scientific literacy merupakan salah satu kemampuan yang penting untuk dimiliki atau dikuasai oleh siswa [I]. Hal ini dikarenakan scientific literacy sebagai kemampuan untuk memahami bagaimana proses sains dan menerapkan pengetahuan yang dimiliki dalam kehidupan sehari-hari [2].

Salah satu penilaian PISA (Programme International for Student Assessment) 2015 ialah scientific literacy. Sekali dalam waktu 3 tahun, Indonesia dengan konsisten ikutserta dalam penilaian PISA. Pada tahun 20I5, peningkatan point Indonesia terbesar terlihat pada kompetensi sains yaitu 382 poin menjadi 403 poin.

Selain aspek kompetensi, scientific literacy juga mencakup beberapa aspek meliputi konteks, pengetahuan, kompetensi dan sikap [3]. Sedangkan pada Scientific literacy draft framework 2015, aspek tersebut berubah menjadi competencies, type of scientific knowledge, contexts dan cognitive demand.

Dalam upaya mengetahui kemampuan siswa dapat dilakukan melalui penilaian. Penilaian menjadi salah satu komponen penting dalam belajar dan pembelajaran [4]. Penilaian juga fokus dalam konsteks Science, Technology, Engineering dan Mathematics (STEM). PISA juga mempertimbangkan literasi untuk melibatkan kapasistas lintas disiplinary orang-orang dalam mengaplikasikan pengetahuan dan kemampuan dalam area konten yang berbeda dan untuk menganalisis, alasan dan komunikasi sebagai siswa dalam bersikap, menyelesaikan dan menyimpulkan beragam permasalah kehidupan nyata [5]. 
Penelitian mengenai scientific literacy pernah dilakukan. Penerapan pendekatan saintifik model 5M dalam pembelajaran fisika dapat meningkatkan scientific literacy yang ditunjukkan rata-rata $\mathrm{N}$-gain sebesar 0,54 dikategorikan sedang [6]. Selain itu, analisis scientific literacy siswa dilakukan untuk mengetahui kemampuan scientific literacy siswa pada materi hukum-hukum dasar kimia. Hasil analisis menunjukkan bahwa nilai rata-rata kemampuan scientific literacy siswa dari stata atas memiliki kemamupuan literasi nominal, konseptual dan multidimensional lebih tinggi dibandingkan strata menengah dan bawah[7]. Namun, penelitian khusus pada materi fluida statis jarang dilakukan.

Pendekatan yang menginterasikan berbagai bidang ialah STEM. STEM akan berkolaborasi dengan pembelajaran berbasis masalah sehingga pembelajaran yang diterapkan lebih dikenal dengan sebutan STEM berbasis Masalah. Penelitian ini dilakukan untuk mengetahui bagaimana peningkatan scientific literacy siswa pada pembelajaran STEM berbasis masalah.

\section{Kajian Pustaka}

\section{Scientific literacy}

Scientific literacy merupakan kemampuan untuk memahami proses sains dan untuk mengikutsertakan dengan memanfaatkan informasi sains yang tersedia dalam kehidupan sehari-hari [2]. Pembelajaran bermakna saat pemahaman cara relevan secara personal sebagai hubungan pengetahuan yang lalu dengan pengetahuan yang baru. Pendidik dan pembuat kebijakan telah menyusun ulang untuk meningkatkan pendidikan sains K-I2 dan mendefinikan ekspektasi performance untuk menguatkan kebutuhan sais sebagai penyelidikan untuk peningkatan scientific literacy [8].

Beberapa kategosi scientific literacy dalam the 2015 Scientific Literacy draft framework [9] sebagai berikut

\section{I) Competences}

Ada 3 kompetensi yang diperlukan untuk literasi sains meliputi menjelaskan fenomena secara ilmiah, mengevaluasi dan design penyelidikan ilmiah, menginterprestasikan data dan bukti secara ilmiah.

2) Types of Scientific Knowledge

Ada 3 tipe Scientific Knowledge meliputi Content Knowledge, Procedural Knowledge, dan Epistemic Knowledge

3) Contexts

Contexts mencakup kesehatan, sumber alami, lingkungan, bahaya dan batas science dan technology di dalam personal, lokal/ nasional dan pengaturan global.

\section{4) Cognitive demand}

Ini merupakan fitur baru dalam 2015 PISA Framework merupakan definisi tingkat congnitive demand dalam penilaian scientific literacy dan persilangan semua tiga kompetensi dalam framework. Level dalam penilaian ini mencakup low, medium dan high.

\section{STEM}

Istilah STEM sudah popular di beberapa negara. Salah satunya di USA. Di USA, STEM education dilihat sebagai step penting terhadap memastikan kesuksesan mendatang untuk negara [IO]. STEM education hadir dibeberapa faktor. Banyak profesi saat ini yang membutuhkan tempat kerja yang dapat mengikutsertakan dalam pemikiran dan keterampilan STEM seperti kreatifitas, inivasi, berpikir kritis, pemecahan masalah, dan literasi informasi dan media [II]. Selain itu, siswa juga perlu melibatkan STEM thinking dan skills diprediksi untuk meningkatkan sebagai teknologi berkelanjutan dan menjadi lebih tersedia dengan cepat [II,I2].

Pentingnya literasi dalam matematika dan sains adalah ditekankan dengan menilai literasi-literasi ini terpisah dengan program PISA, dimana mempertimbangkan literasi untuk mencakup kemampua untuk menerapkan pengetahuan antar disiplin.

\section{Problem Based Learning}

Problem Based Learning (PBL) ialah suatu pendekatan atau model pembelajaran aktif yang menggunakan permasalah autentik sebagai acuan pembelajaran dan pembelajaran yang berpusat pada siswa[I4]. Pembelajaran problem based learning dimulai dengan masalah dan masalah tersebut sebagai konteks untuk siswa memperoleh pengetahuan [I5].

\section{Metode Penelitian}

Metode penelitian ini ialah metode penelitian deskriptif yang mana bertujuan untuk mendeskripsikan atau menggambarkan fenomena-fenomena yang ada baik fenomena yang terjadi secara alami maupun hasil perlakuan.

Penelitian ini dilakukan di salah satu SMA yang ada di Provinsi Jambi. Subjek penelitian terdiri atas 27 siswa.

Scientific literacy siswa diperoleh melalui pre-test dan post-test. Pre-test dilakukan sebelum pembelajaran dimulai dan post-test lakukan setelah pembelajaran. Intrumen soal terdiri atas 5 soal essay. Intrumen tersebut telah di validasi oleh ahli dan validasi empiris serta memiliki reliabilitas tinggi sebesar.73. Aspek yang diukur meliputi aspek competences, knowledge dan context.

Data pre-test dan post-test di n-gain $(<\mathrm{g}>)$ untuk mengetahui peningkatan.

$$
<g>=\frac{S_{\text {post }}-S_{\text {pre }}}{S_{\text {m-ideal }}-S_{\text {pre }}}
$$


Data pre-test dan post-test dikategorikan menjadi 7 level berdasarkan PISA 2015 [9] meliputi level Ib, level Ia, level I, level 2, level 3, level 4, level 5, level 6.

\section{Hasil Penelitian dan Pembahasan}

Pembelajaran STEM berbasis masalah dilaksanakan selama 4 kali pertemuan. Adapun materi yang disampaikan pada pertemuan-pertemuan tersebut meliputi tekanan hidrostatis, hukum Pascal, hukum Archimedes dan tegangan permukaan.

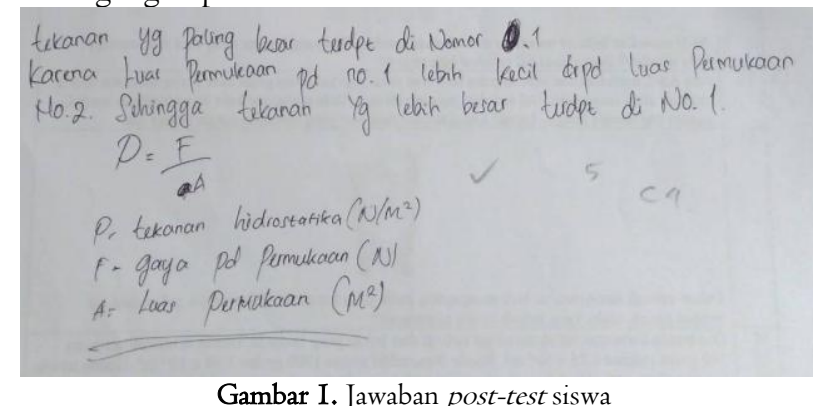

Dalam pembelajaran ini terdiri atas pendahuluan, inti dan penutup. Pada tahap inti terdiri atas beberapa tahap meliputi mengorientasikan siswa pada masalah, mengorganisasikan siswa pada masalah, membimbing penyelidikan individu maupun kelompok, mengembangkan dan menyajikan hasil karya, dan menganalisis dan mengevaluasi proses pemecahan masalah. Scientific literasi menuntuk kemampuan menggunakan proses penyelidikan sains meliputi mengidentifikasi bukti yang diperlukan yang dapat membantu menjawab pertanyaan ilmiah, dan mengenal permasalahan yang dapat dipecahkan melalui penyelidikan ilmiah. Dalam pembelajaran ini dibantu dengan proyektor sebagai upaya membantu dalam mengorientasikan masalah dan alat percobaan sebagai upaya penyelidikan dan membantu memperoleh pengetahuan serta memecahkan masalah. Penggunaan alat-alat bantu ini dipengaruhi oleh kemajuan ilmu pengetahuan dan teknologi [16].

Selain itu, disetiap tahap terdapat pendekatan STEM sehingga memberikan motivasi kepada siswa. mengintegrasikan pembelajaran STEM dapat meningkatkan motivasi siswa dalam pembelajaran[I7]. Hasil scientific literacy siswa ditunjukkan pada tabel I. Scientific Literacy sejajar dengan STEM literacy, contohnya memahami konsep dan keterampilan prosedural dan kemampuan individu untuk mendemonstrasikan hubungan STEM terhadap personal, sosial dan isu global.

Tabel I. Rekapitulasi Scientific Literacy siswa

\begin{tabular}{ccccc}
\hline & N & Min & Max & Mean \\
\hline Pre-test & 27 & 0 & 72 & 27,83 \\
Post-test & 27 & 24 & 96 & 55,11 \\
\hline
\end{tabular}

Berdasarkan analisis data tabel I, pre-test dan post-test menggambarkan hasil tes sebelum dan setelah pembelajaran. Pada pre-test, nilai minimum 0 menunjukkan bahwa tidak menjawab seluruh soal, siswa hanya menulis identitas diri. Siswa mengalami peningkatan scientific literasi setelah pembelajaran STEM berbasis masalah. Siswa yang telah memperoleh pembelajaran STEM akan lebih sadar pada aspek STEM sehingga kemampuan scientific literacy siswa otomatis meningkat[18]. Scientific literacy siswa erat kaitannya dengan literasi teknologi dan matematika [19].

Salah satu jawaban pre-test siswa ditunjukkan pada Gambar I. Siswa dapat menyelesaikan soal tersebut dikarena siswa telah mempelajari literatur yang dimiliki sebelum pre-test. Siswa yang berada pada kategori atas ditempati oleh siswa yang mendapatkan peringkat terbaik di kelas.

Peningkatan pre-test dan post-test diuji menggunakan $\mathrm{n}$-gain. Berdasarkan analisis diperoleh n-gain rata-rata masing-masing soal beragam seperti pada tabel 2 . Nilai n-gain dikategorikan berdasarkan Ref [20]

Tabel 2. Interpretasi rata-rata $\mathrm{N}$-gain pada masing-masing soal

\begin{tabular}{ccc}
\hline $\begin{array}{c}\text { Nomor } \\
\text { Butir Soal }\end{array}$ & Rata-rata N-gain & kategori \\
\hline I & 0,23 & Rendah \\
2 & 0,46 & Sedang \\
3 & 0,25 & Rendah \\
4 & 0,156 & Rendah \\
5 & 0,625 & Sedang \\
\hline
\end{tabular}

Scientific literacy siswa dapat dikategorikan menjadi 7 kriteria berdasarkan PISA 2015 [9]. Hasil pengkategorian tersebut disajikan dalam persentase seperti pada tabel 3 .

Tabel 3. Persentase Kriteria Scientific Literacy Siswa

\begin{tabular}{|c|c|c|c|c|c|c|c|c|}
\hline \multirow{2}{*}{ 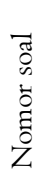 } & \multicolumn{8}{|c|}{ Frekuensi masing-masing soal } \\
\hline & $\begin{array}{c}0 \\
(\%)\end{array}$ & $\begin{array}{c}\mathrm{Ib} \\
(\%)\end{array}$ & $\begin{array}{c}\text { Ia } \\
(\%)\end{array}$ & $\begin{array}{c}2 \\
(\%)\end{array}$ & $\begin{array}{c}3 \\
(\%)\end{array}$ & $\begin{array}{c}4 \\
(\%)\end{array}$ & $\begin{array}{c}5 \\
(\%)\end{array}$ & $\begin{array}{c}6 \\
(\%)\end{array}$ \\
\hline $\mathrm{I}$ & II,I & 7,4 & 22,2 & 29,6 & 7,4 & II,I & 3,74 & 7,4 \\
\hline 2 & 3,7 & $\mathrm{I} 4,8$ & 33,3 & 22,2 & $\mathrm{I} 4,8$ & 3,74 & 7,47 & 0 \\
\hline 3 & $\mathrm{II}, \mathrm{I}$ & 0 & 51,8 & $\mathrm{I} 4,8$ & 18,5 & 0 & 3,74 & 0 \\
\hline 4 & II, I & 0 & 18,5 & 44,4 & $\mathrm{I} 4,8$ & II,I & 0 & 0 \\
\hline 5 & 0 & 0 & 25,9 & 22,2 & 37 & 7,47 & 7,47 & 0 \\
\hline
\end{tabular}

Persentase tersebut menunjukkan jumlah siswa yang masuk level tersebut berdasarkan persentase jumlah siswa di dalam kelas. Seperti pada butir soal nomor, 29,6 \% siswa dikategorikan berada pada level scientific literacy yaitu level 2. Berdasarkan analisis jawaban soal nomor 2 siswa, siswa telah menunjukkan beberapa bukti terkait pemikiran dan penalaran ilmiah. Siswa menginterpretasikan berdasarkan beberapa sumber data 
dan berbagai konteks serta menjelaskan hubungan kausal sederhana.

\section{Kesimpulan}

Hasil analisis n-gain menunjukkan terdapat peningkatan pada masing-masing soal. Pada soal nomor I, 3 dan 4, peningkatan dikategorikan rendah secara berurutan sebesar 0,23, 0,25, 0,I56. Sedangkan pada soal nomor 4, peningkatan dikategorikan sedang karena n-gain sebesar 0,43. Selain itu, n-gain pada soal nomor 5 dikategorikan tinggi karena n-gain sebesar I.

Berdasarkan hasil n-gain menunjukkan bahwa STEM berbasis masalah dapat meningkatkan scientific literacy siswa khususnya pada materi fluida statis. Integrasi pendekatan STEM dapat membantu siswa baik menganalisis masalah maupun memecahkan masalah yang terjadi dalam kehidupan sehari-hari. Pengetahuan yang digunakan untuk memecahkan masalah ialah scientific literacy $[2 \mathrm{I}]$.

\section{Ucapan Terimakasih}

Ucapan terima kasih kepada Indonesia Endowment Fund for Education (LPDP) yang telah mendukung penelitian ini.

\section{Kepustakaan}

[I] E. Gucluer and T. Kesercioglu, "The Effect of Using Activities Improving Scientific Literacy on Students' Achievement in Science and Technology Lesson," Online Submiss., vol. I, no. I, pp. 8-13, 2012.

[2] H. Fives, W. Huebner, A. S. Birnbaum, and M. Nicolich, "Developing a Measure of Scientific Literacy for Middle School Students," Sci. Educ, vol. 98, no. 4, pp. 549-580, 2014.

[3] OECD, PISA 2012 Assessment and Analytical Framework PISA 2012 Assessment and Analytical Framework. 2013.

[4] Y. Shwartz, R. Ben-zvi, and A. Hofstein, "The use of scientific literacy taxonomy for assessing the development of chemical literacy among high-school students," vol. 7, no. 4, pp. 203225, 2006.

[5] T. Larry D, Yore. David, Pimm. \& Hsiao-Lin, "The literacy component of mathematical and scientific literacy," Int. J. Sci. Math. Educ., vol. 5, no. July, pp. 559-589, 2007.

[6] C. Rochman, "Penerapan Pembelajaran Berbasis Scientific Approach Model 5M dan Analisis Kemampuan Literasi Sains Peserta Didik pada Sekolah Mitra Universitas Islam Negeri Sunan Gunung Djati Bandung," pp. 435-440, 2015.

[7] A. Ali, I. Ardiansyah, D. Irwandi, and D. Murniati, "Analisis Literasi Sains Pada Materi Hukum Dasar Kimia Di Jakarta Selatan," EduChemia, vol. I, no. 2, pp. I49-I6I, 2016.

[8] A. Schleicher, "PISA 2006: Science Competencies for Tomorrow's World OECD briefing note for the United States," no. December, 2007.

[9] I. Produced, "OECD Programme for International Student Assessment 2015 PISA 2015 RELEASED FIELD TRIAL," 2015.

[10] Academies National, Rising Above the Gathering Storm: Energizing and Employing America for a Brighter Economic Future. Washington: National Academies Press, 2007.
[II] M. Kennedy, T J. and Odell, "Engaging Students In STEM Education," vol. 25, no. 3, pp. 246-258, 2014.

[12] A. Johnson, L., Adams Becker, S., Estrada, V.,\&Freeman, NMC horizon report: 2015 K-I2 edition. Austin: The New Media Consortium., 2015.

[13] H. B. Gonzalez and J. J. Kuenzi, "Science, Technology, Engineering, and Mathematics (STEM) Education: A Primer," Congr. Res. Serv. Libr. Congt., 2012.

[14] I. Bilgin, E. Ş enocak, and M. Sözbilir, "The effects of problembased learning instruction on university students' performance of conceptual and quantitative problems in gas concepts," Eurasia J. Math. Sci. Technol. Educ., vol. 5, no. 2, pp. I53I64, 2009.

[I5] E. Maryam, "Pengaruh Menggunakan Model PBL ( Problem Based Learning ) Terhadap Hasil Belajar IPA Fisika SMP N 7 Kota Bengkulu," vol. 4, no. I, pp. I8-2I, 2017.

[16] Y. N. Silta, "Pengembangan Sensor Air Hujan Menggunakan Hukum Archimedes Untuk Jemuran Pakaian Otomatis Berbasis Lingkungan Sebagai Media Pembelajaran Fisika," vol. 2, no. I, pp. 33-37, 2015.

[17] J. T. Guthrie, A. Wigfield, and C. Vonsecker, "Effects of Integrated Instruction on Motivation and Strategy Use in Reading," vol. 92, no. 2, pp. 33I-34I, 2000.

[18] dan I. H. N Khoeruningtyas, A Permanasari, "STEM learning in Material of Temperature and its Change to Improve Scientific Literacy of Junior High School.," J. Pendidik. IPA Indones., vol. 5, no. I, pp. 94-100, 2016.

[19] A. Permanasari, "STEM Education : Inovasi dalam Pembelajaran Sains," pp. 23-34, 2016.

[20] R. R. Hake, "Interactive-engagement versus traditional methods: A six-thousand-student survey of mechanics test data for introductory physics courses," Am. J. Phys., vol. 66, no. I, pp. 64-74, 1998 .

[2I] I. Ismail, A. Permanasari, and W. Setiawan, "Efektivitas Virtual Lab Berbasis STEM dalam Meningkatkan Literasi Sains Siswa dengan Perbedaan Gender STEM-Based Virtual Lab Effectiveness in Improving the Scientific Literacy of Students with Gender Differences," vol. 2, no. 2, pp. 190-201, 2016. 